\title{
Quality and Safety Aspects of Infant Nutrition
}

\author{
Berthold Koletzko $^{a}$ Raanan Shamir ${ }^{b}$ Margaret Ashwell ${ }^{c}$ \\ on behalf of the Early Nutrition Academy (ENA) and the European Society \\ for Paediatric Gastroenterology, Hepatology and Nutrition (ESPGHAN) \\ ${ }^{a}$ Dr. von Hauner Children's Hospital, University of Munich Medical Centre, Munich, Germany; ${ }^{b}$ Schneider Children's \\ Medical Center of Israel, Sackler Faculty of Medicine, Tel Aviv University, Tel Aviv, Israel; 'Ashwell Associates Ltd., \\ Ashwell, UK
}

\section{Key Words}

Food safety $\cdot$ Infant formula $\cdot$ Follow-on formula .

Complementary feeding $\cdot$ Breast-feeding

\begin{abstract}
Quality and safety aspects of infant nutrition are of key importance for child health, but oftentimes they do not get much attention by health care professionals whose interest tends to focus on functional benefits of early nutrition. Unbalanced diets and harmful food components induce particularly high risks for untoward effects in infants because of their rapid growth, high nutrient needs, and their typical dependence on only one or few foods during the first months of life. The concepts, standards and practices that relate to infant food quality and safety were discussed at a scientific workshop organized by the Child Health Foundation and the Early Nutrition Academy jointly with the European Society for Paediatric Gastroenterology, Hepatology and Nutrition, and a summary is provided here. The participants reviewed past and current issues on quality and safety, the role of different stakeholders, and recommendations to avert future issues. It was concluded that a high level of quality and safety is currently achieved, but this is no reason for complacency. The food industry carries the primary responsibility for the safety and suitability of their products, including the quality of composition, raw materials and production processes. Introduction of new or modified products should be
\end{abstract}

preceded by a thorough science based review of suitability and safety by an independent authority. Food safety events should be managed on an international basis. Global collaboration of food producers, food-safety authorities, paediatricians and scientists is needed to efficiently exchange information and to best protect public health.

Copyright $\odot 2012$ S. Karger AG, Basel

The interest of pediatricians, other health care professionals, and the public in infant nutrition products is often focused on possible functional effects, such as potential risk reduction of allergic disorders or the potential benefits for child development or long-term health $[1,2]$. In contrast, pediatricians and other health care professionals often assume quality and safety as a matter of course and do not devote the same level of attention to these aspects.

However, quality and safety issues are of key importance for infant feeding and child health. Suitability and safety are fundamental regulatory requirements for allowing the marketing of infant food products [3]. These aspects are important because infants carry particularly high risks for untoward effects of unbalanced diets or of harmful food components. Why? Because they grow rapidly and have high nutrient needs, and because during the first months after birth usually one sole milk source must meet all the dietary requirements. Further, immature and

\section{KARGER \\ Fax +4161306 1234 \\ E-Mail karger@karger.ch}

www.karger.com
(C) 2012 S. Karger AG, Basel

0250-6807/12/0603-0179\$38.00/0

Accessible online at:

www.karger.com/anm
Prof. Berthold Koletzko

Dr. von Hauner Children's Hospital, University of Munich Medical Centre Lindwurmstrasse 4

DE-80337 Munich (Germany)

E-Mail office.koletzko@med.uni-muenchen.de 
rapidly developing infants have a high susceptibility to harmful effects from many exposures.

Breast-feeding is regarded as the optimal form of nutrition for human infants because of its numerous health advantages, including, for example, prevention of infectious diseases, promotion of neurodevelopment, and reduced risk of later obesity, diabetes, and hypertension [4-6]. Despite these recommendations, the vast majority of infants worldwide receive some infant formula at some time during their first year of life, whether as their sole source of nutrition or in combination with human milk, or homemade or commercial complementary foods. Hence, the concepts, standards, and practices that relate to the quality and safety of food products for infants are of great public health importance.

A workshop was held in Sorrento, Italy, in May 2011, on behalf of the charitable Child Health Foundation, Munich (www.kindergesundheit.de) and the Early Nutrition Academy (www.early-nutrition.org), in collaboration with the European Society for Pediatric Gastroenterology, Hepatology and Nutrition (www.espghan.org) to review and discuss some of the key questions in this area. They specifically addressed the following questions:

(1) What lessons have we learned from past issues of quality and safety?

(2) What do we agree are the current issues for quality and safety?

(3) What do we predict might be future issues for quality and safety and why?

(4) Which stakeholders should worry about current and future quality and safety issues (manufacturers, government, health professionals, others)? Why are they issues for them?

(5) What recommendations do we agree for these stakeholder groups to improve concerning any current issues and to avert any predicted future issues?

This report summarizes some general issues addressed by the workshop. It is complemented by a series of reports published in this issue of the journal which provide summaries and key conclusions of presentations held at the workshop.

\section{Safety Issues: Nutrient Contents}

Standards and regulations for infant formula and other infant foods aim at ensuring high levels of safety and are much more rigorous than regulations for other food products [3, 7-9]. In fact, it was a serious safety issue that led to the adoption of the US Infant Formula Act in 1980.
The issue was the change in the formulation of two soy infant formulae which were introduced in 1978 by a major infant formula manufacturer in the USA, with a marked reduction in the sodium chloride content. These chloride deficient formulations induced hypochloremic metabolic alkalosis and growth faltering in the babies who received them, and they were later also found to be associated with adverse long-term effects on developmental outcomes and with behavioral problems [10-13]. The United States Congress reviewed the matter and determined that protection of infants fed infant formulae needed to be improved by greater regulatory control over infant formula, which led to the US Infant Formula Act of 1980 (Pub. L 96-359). This act first established minimum nutrient requirements for infant formulae, defined adulteration and quality control procedures, and specified inspection requirements as well as recall procedures [9].

The establishment of this and further national, regional, and global standards and regulations on infant formulae and baby foods has contributed to the very high level of safety of such products that exists today. Compared to the enormous number of infants fed such products on a daily basis, only a very small number of adverse events has become known.

However, in spite of established standards and regulations, the occurrence of nutrient deficiency due to compositional errors can still occur. In 2003, a thiamine deficient soy protein-based infant formula led to severe thiamine deficiency in recipient infants with lactic acidosis, encephalopathy, cardiomyopathy, and deaths [14, 15], along with long-term neurologic problems in surviving children [16-18]. This tragedy apparently resulted from an error of the manufacturer in designing the nutrient composition of the formula $[19,20]$, and it calls for the application of even more stringent quality control measures.

Not only nutrient deficiency, but also too high nutrient intakes may cause adverse effects. An excessive supply of dietary components, and the supply of unnecessary components, can put a burden on the infant's metabolic and other functions. Dietary components that are not utilized or stored by the body must be excreted as such or in the form of metabolites, in most cases as solutes with the urine. However, water available to form urine is limited, and infants particularly during the first months of life have a limited ability to concentrate urine. Therefore, the need to excrete any additional solutes can reduce the margin of safety, particularly if the infant is stressed by fever or diarrhea.

An impressive example of untoward effects of a too high nutrient intake is the observation that an additional daily iron intake of $1 \mathrm{mg} / \mathrm{kg}$ from 6 to 9 months of age 
induces significantly impaired length growth in iron sufficient infants $[21,22]$. Therefore, it is important to define not only adequate minimum but also maximum ingredient contents in infant food products [8].

\section{Adulteration}

Probably the largest infant food safety problem ever occurred in 2008 in China: infant formula was produced from milk to which melamine had been added to sham a higher protein content, which caused urolithiasis and related damage in a large number of infants [23-27]. It is estimated that more than 300,000 infants were exposed to such adulterated formula, with tens of thousands of hospitalizations and 6 reported deaths $[27,28]$. This intentional milk contamination with melamine had international implications due to the global distribution of these products and delayed reporting. This led to exposure to melamine-contaminated products originating from China, or to products containing contaminated ingredients from China, not only across Asia but also in Africa, Australia/New Zealand, Europe, and North America [25, 28].

Another case of adulteration became known in 2011, when a major incident of phthalate-contaminated foodstuffs occurred in Taiwan. The toxic compounds di-(2ethylhexyl)phthalate and diisononyl phthalate were deliberately added to foodstuffs to substitute for an emulsifier, including foods that were consumed by infants [29]. Again, phthalate-contaminated products were exported to and found in several other countries. The supply of phthalate to infants is of concern, since phthalate exposure in early life has been associated with endocrine disrupting effects, impaired growth, mental and motor development, and increased risk for heart defects [30-33].

\section{Microorganisms and Their Toxins}

Food products, including powdered infant formulae, are not sterile but may contain viable microorganisms, including pathogens such as Salmonella enterica, Salmonella typhi, Shigella dysenteriae or Cronobacter sakazakii [34-36] that can cause serious infections in infants. In recent years, there have been numerous recurrences of invasive infections with Cronobacter sakazakii that led to bacteremia, necrotizing enterocolitis and meningitis predominantly in premature infants - which were related to the consumption of infant formula reconstituted from powder contaminated with these bacteria [37-40]. Oc-

Quality and Safety of Infant Nutrition currence of invasive infections occurred after prolonged storage of reconstituted formula at warm temperatures which can lead to a marked increase in bacterial numbers and hence reach an infective dose [41, 42]. Reij et al. [43] recently estimated the burden of disease of Cronobacter infections in infants to the Dutch population as 19-24 disability-adjusted life years (DALYs) per year, of which $95 \%$ are due to meningitis. Based on these estimates, Cronobacter infections represent $0.5-2.4 \%$ of the total estimated burden of foodborne infections and intoxications and would be responsible for $0.5-0.7 \%$ of the meningitis burden to the entire Dutch population. Due to such concerns, numerous product recalls of powdered infant formulae batches in which C. sakazakii had been detected, even at low numbers, have occurred. Some experts and authorities have also recommended the preparation of all infant formulae with water heated to at least $70^{\circ} \mathrm{C}$ to inactivate live bacteria. However, it is unclear whether this measure reduces infection risks in newborn, term or older infants if prolonged formula storage is avoided. At the same time, preparation of infant formula with water heated to at least $70^{\circ} \mathrm{C}$ will definitely reduce its nutritional quality $[42,44,45]$ and increases the risk of scalding injuries from hot water which frequently occur in infants [46].

Safety concerns due to microbial contamination are not limited to commercial infant foods. Human breast milk and homemade complementary foods may bear significant contamination with microorganisms and aflatoxins, particularly in low-income countries [47-50], whereas commercial baby foods generally contain very low amounts of mycotoxins [51]. Aflatoxin contamination of foods contributes a significant public health burden in low-income countries due to their carcinogenicity and their growth-impairing effects in children [52].

\section{Contaminants and Residues}

European legislation stipulates the absence of appreciable contaminant levels in foodstuffs for particular nutritional uses intended for infants and young children, which includes infant and follow-on formulae and commercial baby foods, with a very low common limit for pesticide residues of $0.01 \mathrm{mg} / \mathrm{kg}(1 \mathrm{ppm})$ considered to be close to the minimum detectable level [3]. Nonetheless, a minimal residual risk cannot be excluded with absolute certainty. For example, concern has been raised regarding the exposure to endocrine disruptors through infant foods with respect to potential impact on health, given 
that infants are thought to be more sensitive to hormonal impacts of environmental chemicals than adults [53].

Exposure to other contaminants must also be considered. For example, in parenterally fed premature infants, aluminum exposure from glassware was related to impaired developmental outcomes. In a randomized clinical trial, premature infants exposed for $>10$ days to standard parenteral feeding solutions had more impaired neurologic development at 18 months than infants randomized to solutions especially sourced for low aluminium content [54]. Therefore, it is now recommended to limit aluminium exposure of parenterally fed children as much as possible, and to avoid the repeated use of calcium gluconate in small-volume glass containers for treatment in children up to 18 years of age [54]. Significant aluminium contents have also been found in some infant formulae, including soy protein-based formulae as well as lactose-free, hypoallergenic, and preterm formulae, but it remains unknown whether the enteral exposure to these aluminium concentrations has any relevant biological effects $[55,56]$. A recent model calculation estimated that the total body burden of aluminium in healthy infants from both vaccines and diet throughout the first year of life is significantly lower than the corresponding safe body burden of aluminium, using the regulatory minimum risk level [57].

Among the contaminants that can be newly formed during the production of foodstuffs are furan and acrylamide. Furan is formed under heat exposure from carbohydrates, ascorbic acid, and polyunsaturated fatty acids. Furan has been classified as a 'possible human carcinogen' and is found in low concentrations in some baby foods $[58,59]$. Acrylamide, another possible carcinogen, is formed during heating of starchy foods for longer periods of time and has been detected in low amounts in infant formulae and commercial baby foods [60]. Much higher concentrations of acrylamide can occur in homemade and general foods fed to infants and young children, who reach much higher exposures than all other parts of the population $[61,62]$. The European Commission has recommended to monitor the content of major newly formed contaminants, such as acrylamide and furan, in food products and to aim at achieving low levels whenever possible $[63,64]$. Industry has taken active measures to minimize contents of newly formed contaminants in food products $[65,66]$.

In addition to components derived from the raw material and the production process of foodstuffs, also packaging materials and feeding devices can add to the exposure to substances with potentially untoward effects. For example, the migration of significant amounts of potentially toxic components from baby bottles into feeds, such as bisphenol A (BPA), plasticizers, esters, and certain antioxidants, must be avoided [67-69].

\section{Conclusions}

The experts attending this workshop emphasized that, currently, a very high level of quality and safety in infant feeding is achieved but agreed that this was no reason for complacency. The public expectation is that infant feeding should be absolutely safe, that is $100 \%$ free of any risks for or any harm to the baby. However, from a scientific perspective an absolute safety cannot be guaranteed, but rather one aims at the highest level of risk reduction that is achievable, i.e. the approach has to be one of relative safety, which is not always an easy concept to explain to the public.

There was agreement that the introduction of new or modified infant food products should be preceded by a systematic review of the available evidence, and usually preclinical safety assessment followed by evaluation in clinical trials according to current scientific standards [70-73]. Consumers and health care professionals expect any new ingredient to be thoroughly tested by scrupulously conducted clinical trials which usually assess growth, monitor adverse events, and are evaluated by the appropriate regulatory body (EFSA for Europe, GRAS status and FDA in the USA) [74, 75]. The pediatric participants at the workshop agreed that the introduction of new or modified infant food products into the market should require an evaluation of their suitability and safety by an independent authority, which at present is the case, for example, in the USA and Australia but not in Europe [74, 75].

The food industry is expected to use safe and suitable ingredients that meet the highest purity standards and assume that these are present in the infant foods at levels (lower and upper) stipulated by legislation. Control of ingredient quality and of good manufacturing practice appears to be of great importance for ensuring product safety, and weaknesses regarding these aspects appear to have contributed to the frequent recalls and warnings on infant food products that appeared in recent years. Such incidents appear to happen mostly because of violation of good production process standards and/or insufficient control of the supplied ingredients. Moreover, there may be considerable pressure to reduce cost of production, which could create incentives to compromise on quality. 
Human error is often found to be the primary cause, but the impact of human error can best be minimized by employing the highest possible quality and safety standards, which the industry is encouraged to implement.

The scientific experts attending this workshop agreed that managing food safety events should be done on an international basis. Global collaboration of food producers, food safety authorities, and scientists is needed to efficiently exchange information and to best protect public health.

\section{Acknowledgements}

Partial financial support from the Commission of the European Community, specific RTD Programme 'Quality of Life and Management of Living Resources', within the 7th Framework Programme, research grant No. FP7-KBBE-2011-5-289346 (EARLY NUTRITION) is gratefully acknowledged. This paper does not necessarily reflect the views of the Commission and in no way anticipates the future policy in this area. We thank Abbott Nutrition, Danone Research, Dairy Goat Cooperative, DSM Nutritional Products, Hipp GmbH, Mead Johnson Nutritionals and United Pharmaceuticals for additional support through unrestricted educational grants.

\section{References}

1 Koletzko B, Aggett PJ, Bindels JG, et al: Growth, development and differentiation: a functional food science approach. Br J Nutr 1998;80(suppl 1):S5-S45.

2 Szajewska H, Makrides M: Is early nutrition related to short-term health and long-term outcome? Ann Nutr Metab 2011;58(suppl 1):38-48.

3 European-Commission: Commission Directive 2006/141/EC of 22 December 2006 on infant formulae and follow-on formulae and amending Directive 1999/21/EC. Official Journal of the European Union 2006;L 401/1 20.12.2006.

4 Agostoni C, Braegger C, Decsi T, et al: Breastfeeding: a commentary by the ESPGHAN Committee on Nutrition. J Pediatr Gastroenterol Nutr 2009;49:112-125.

-5 Koletzko B, von Kries R, Monasterolo RC, et al: Infant feeding and later obesity risk. Adv Exp Med Biol 2009;646:15-29.

-6 Rebhan B, Kohlhuber M, Schwegler U, Fromme H, Abou-Dakn M, Koletzko BV: Breastfeeding duration and exclusivity associated with infants' health and growth: data from a prospective cohort study in Bavaria, Germany. Acta Paediatr 2009;98:974-980.

-7 Zlotkin S, Siekmann J, Lartey A, Yang Z: The role of the Codex Alimentarius process in support of new products to enhance the nutritional health of infants and young children. Food Nutr Bull 2010;31:S128-S133.

8 Koletzko B, Baker S, Cleghorn G, et al: Global standard for the composition of infant formula: recommendations of an ESPGHAN coordinated international expert group. J Pediatr Gastroenterol Nutr 2005;41:584599.

$\checkmark 9$ Newberry RE: The Infant Formula Act of 1980. J Assoc Off Anal Chem 1982;65:14721473.

10 Kaleita TA: Neurologic/behavioral syndrome associated with ingestion of chloridedeficient infant formula. Pediatrics 1986;78: 714-715.
11 Malloy MH, Graubard B, Moss H, et al: Hypochloremic metabolic alkalosis from ingestion of a chloride-deficient infant formula: outcome 9 and 10 years later. Pediatrics 1991; 87:811-822.

12 Silver LB, Levinson RB, Laskin CR, Pilot LJ: Learning disabilities as a probable consequence of using chloride-deficient infant formula. J Pediatr 1989;115:97-99.

13 Willoughby A, Graubard BI, Hocker A, et al: Population-based study of the developmental outcome of children exposed to chloridedeficient infant formula. Pediatrics 1990;85: 485-490.

14 Fattal-Valevski A, Kesler A, Sela BA, et al: Outbreak of life-threatening thiamine deficiency in infants in Israel caused by a defective soy-based formula. Pediatrics 2005; 115:e233-e238.

15 Kornreich L, Bron-Harlev E, Hoffmann C, et al: Thiamine deficiency in infants: MR findings in the brain. AJNR Am J Neuroradiol 2005;26:1668-1674.

16 Lanska DJ, Fatal-Valevski A: Epilepsy in children with infantile thiamine deficiency. Neurology 2010;74:702-703; author reply 703 .

17 Fattal-Valevski A, Azouri-Fattal I, Greenstein YJ, Guindy M, Blau A, Zelnik N: Delayed language development due to infantile thiamine deficiency. Dev Med Child Neurol 2009;51:629-634.

18 Fattal-Valevski A, Bloch-Mimouni A, Kivity $\mathrm{S}$, et al: Epilepsy in children with infantile thiamine deficiency. Neurology 2009;73: 828-833.

19 Aris B: Maker of vitamin B1-deficient baby milk admits error. Lancet 2003;362:1730.

20 Shamir R: Thiamine-deficient infant formula: what happened and what have we learned? Ann Nutr Metab 2012;60:185-187.

-21 Dewey KG, Domellof M, Cohen RJ, Landa Rivera L, Hernell O, Lonnerdal B: Iron supplementation affects growth and morbidity of breast-fed infants: results of a randomized trial in Sweden and Honduras. J Nutr 2002; 132:3249-3255.

22 Domellof M: Iron requirements in infancy. Ann Nutr Metab 2011;59:59-63.
23 Chang H, Shi X, Shen W, Wang W, Yue Z: Characterization of melamine-associated urinary stones in children with consumption of melamine-contaminated infant formula. Clin Chim Acta 2012;413:985-991.

24 Panfeng S, Hong C, Zhongjin Y, et al: Management of pediatric urolithiasis induced by melamine-contaminated powdered formula (report of 619 cases). Urology 2011;78:411-416.

25 Schoder D: Melamine milk powder and infant formula sold in East Africa. J Food Prot 2010;73:1709-1714.

26 Shang P, Chang H, Yue ZJ, et al: Acute kidney injury caused by consumption of melaminecontaminated infant formula in 47 children: a multi-institutional experience in diagnosis, treatment and follow-up. Urol Res 2011, E-pub ahead of print.

27 Wei Y, Liu D: Review of melamine scandal: still a long way ahead. Toxicol Ind Health 2011, E-pub ahead of print.

28 Gossner CM, Schlundt J, Ben Embarek P, et al: The melamine incident: implications for international food and feed safety. Environ Health Perspect 2009;117:1803-1808.

$29 \mathrm{Wu}$ MT, Wu CF, Wu JR, et al: The public health threat of phthalate-tainted foodstuffs in Taiwan: the policies the government implemented and the lessons we learned. Environ Int 2012, E-pub ahead of print.

- 30 Whyatt RM, Liu X, Rauh VA, et al: Maternal prenatal urinary phthalate metabolite concentrations and child mental, psychomotor, and behavioral development at 3 years of age. Environ Health Perspect 2012;120:290-295.

-31 Snijder CA, Roeleveld N, Te Velde E, et al: Occupational exposure to chemicals and fetal growth: the Generation R Study. Hum Reprod 2012;27:910-920.

- 32 Snijder CA, Vlot IJ, Burdorf A, et al: Congenital heart defects and parental occupational exposure to chemicals. Hum Reprod 2012;27:1510-1517.

33 Yen TH, Lin-Tan DT, Lin JL: Food safety involving ingestion of foods and beverages prepared with phthalate-plasticizer-containing clouding agents. J Formos Med Assoc 2011; 110:671-684. 
-34 Cahill SM, Wachsmuth IK, Costarrica Mde L, Ben Embarek PK: Powdered infant formula as a source of Salmonella infection in infants. Clin Infect Dis 2008;46:268-273.

- 35 Flores JP, Medrano SA, Sanchez JS, Fernandez-Escartin E: Two cases of hemorrhagic diarrhea caused by Cronobacter sakazakii in hospitalized nursing infants associated with the consumption of powdered infant formula. J Food Prot 2011;74:2177-2181.

- 36 Day JB, Sharma D, Siddique N, et al: Survival of Salmonella typhi and Shigella dysenteriae in Dehydrated Infant Formula. J Food Sci 2011;76:M324-M328.

37 Yan QQ, Condell O, Power K, Butler F, Tall $\mathrm{BD}$, Fanning S: Cronobacter species (formerly known as Enterobacter sakazakii) in powdered infant formula: a review of our current understanding of the biology of this bacterium. J Appl Microbiol 2012, E-pub ahead of print.

- 38 Norberg S, Stanton C, Ross RP, Hill C, Fitzgerald GF, Cotter PD: Cronobacter spp. in powdered infant formula. J Food Prot 2012;75:607-620.

-39 Jongenburger I, Reij MW, Boer EP, Gorris LG, Zwietering MH: Actual distribution of Cronobacter spp. in industrial batches of powdered infant formula and consequences for performance of sampling strategies. Int J Food Microbiol 2011;151:62-69.

40 Kim SA, Oh SW, Lee YM, et al: Microbial contamination of food products consumed by infants and babies in Korea. Lett Appl Microbiol 2011;53:532-538.

-41 Miled RB, Guillier L, Neves S, Augustin JC, Colin P, Besse NG: Individual cell lag time distributions of Cronobacter (Enterobacter sakazakii) and impact of pooling samples on its detection in powdered infant formula. Food Microbiol 2011;28:648-655.

-42 Agostoni C, Axelsson I, Goulet O, et al: Preparation and handling of powdered infant formula: a commentary by the ESPGHAN Committee on Nutrition. J Pediatr Gastroenterol Nutr 2004;39:320-322.

-43 Reij MW, Jongenburger I, Gkogka E, Gorris LG, Zwietering MH: Perspective on the risk to infants in the Netherlands associated with Cronobacter spp. occurring in powdered infant formula. Int J Food Microbiol 2009;136: 232-237.

44 Davanzo R, Giurici N, Demarini S: Hot water and preparation of infant formula: how hot does it have to be to be safe? J Pediatr Gastroenterol Nutr 2010;50:352-353.

-45 Turck D: Safety aspects in preparation and handling of infant food. Ann Nutr Metab 2012;60:211-214.

-46 Guzel A, Aksu B, Aylanc H, Duran R, Karasalihoglu S: Scalds in pediatric emergency department: a 5-year experience. J Burn Care Res 2009;30:450-456.

47 Oluwafemi F, Ibeh IN: Microbial contamination of seven major weaning foods in Nigeria. J Health Popul Nutr 2011;29:415-419.
48 El-Tras WF, El-Kady NN, Tayel AA: Infants exposure to aflatoxin $\mathrm{M}$ as a novel foodborne zoonosis. Food Chem Toxicol 2011;49:28162819.

49 Kvist LJ, Larsson BW, Hall-Lord ML, Steen A, Schalen C: The role of bacteria in lactational mastitis and some considerations of the use of antibiotic treatment. Int Breastfeed J 2008;3:6.

50 Weistaub G, Uauy R: Non-breast milk feeding in developing countries: challenge from microbial and chemical contaminants. Ann Nutr Metab 2012;60:215-219.

51 Bonerba E, Conte R, Ceci E, Tantillo G: Assessment of dietary intake of patulin from baby foods. J Food Sci 2010;75:T123-T125.

52 Khlangwiset P, Shephard GS, Wu F: Aflatoxins and growth impairment: a review. Crit Rev Toxicol 2011;41:740-755.

53 Raecker T, Thiele B, Boehme RM, Guenther $\mathrm{K}$ : Endocrine disrupting nonyl- and octylphenol in infant food in Germany: considerable daily intake of nonylphenol for babies. Chemosphere 2011;82:1533-1540.

-54 Fewtrell MS, Edmonds CJ, Isaacs E, Bishop NJ, Lucas A: Aluminium exposure from parenteral nutrition in preterm infants and later health outcomes during childhood and adolescence. Proc Nutr Soc 2011;70:299304.

-55 Dabeka R, Fouquet A, Belisle S, Turcotte S: Lead, cadmium and aluminum in Canadian infant formulae, oral electrolytes and glucose solutions. Food Addit Contam Part A Chem Anal Control Expo Risk Assess 2011; 28:744-753.

56 Agostoni C, Axelsson I, Goulet O, et al: Soy protein infant formulae and follow-on formulae: a commentary by the ESPGHAN Committee on Nutrition. J Pediatr Gastroenterol Nutr 2006;42:352-361.

57 Mitkus RJ, King DB, Hess MA, Forshee RA, Walderhaug MO: Updated aluminum pharmacokinetics following infant exposures through diet and vaccination. Vaccine 2011; 29:9538-9543.

58 Ruiz E, Santillana MI, Nieto MT, Cirugeda ME, Sanchez JJ: Determination of furan in jarred baby food purchased from the Spanish market by headspace gas chromatographymass spectrometry (HS-GC-MS). Food Addit Contam Part A Chem Anal Control Expo Risk Assess 2010;27:1208-1214.

-59 Pavesi Arisseto A, Vicente E, De Figueiredo Toledo MC: Determination of furan levels in commercial samples of baby food from Brazil and preliminary risk assessment. Food Addit Contam Part A Chem Anal Control Expo Risk Assess 2010;27:1051-1059.

60 Erkekoglu P, Baydar T: Toxicity of acrylamide and evaluation of its exposure in baby foods. Nutr Res Rev 2010;23:323-333.

61 Hilbig A, Freidank N, Kersting M, Wilhelm $\mathrm{M}$, Wittsiepe J: Estimation of the dietary intake of acrylamide by German infants, children and adolescents as calculated from di- etary records and available data on acrylamide levels in food groups. Int $\mathrm{J}$ Hyg Environ Health 2004;207:463-471.

62 Hirvonen T, Jestoi M, Tapanainen H, et al: Dietary acrylamide exposure among Finnish adults and children: the potential effect of reduction measures. Food Addit Contam Part A Chem Anal Control Expo Risk Assess 2011;28:1483-1491.

63 Birlouez-Aragon I, Morales F, Fogliano V, Pain JP: The health and technological implications of a better control of neoformed contaminants by the food industry. Pathol Biol (Paris) 2010;58:232-238.

64 Commission Recommendation of 2 June 2010 on the monitoring of acrylamide levels in food (Text with EEA relevance) (2010/307/ EU). Official Journal L 137, 03/06/2010 P $0004-0010 ; 2010$.

65 Friedman M, Levin CE: Review of methods for the reduction of dietary content and toxicity of acrylamide. J Agric Food Chem 2008; 56:6113-6140.

66 Hamrin P, Hoeft B: Quality control throughout the production process of infant food. Ann Nutr Metab 2012;60:208-210.

67 Simoneau C, Valzacchi S, Morkunas V, Van den Eede L: Comparison of migration from polyethersulphone and polycarbonate baby bottles. Food Addit Contam Part A Chem Anal Control Expo Risk Assess 2011;28: 1763-1768.

68 Simoneau C, Van den Eede L, Valzacchi S: Identification and quantification of the migration of chemicals from plastic baby bottles used as substitutes for polycarbonate. Food Addit Contam Part A Chem Anal Control Expo Risk Assess 2012;29:469-480.

69 Santillana MI, Ruiz E, Nieto MT, et al: Migration of bisphenol A from polycarbonate baby bottles purchased in the Spanish market by liquid chromatography and fluorescence detection. Food Addit Contam Part A Chem Anal Control Expo Risk Assess 2011; 28:1610-1618.

70 Fewtrell MS: Clinical safety assessment of infant nutrition. Ann Nutr Metab 2012; 60:200-203.

71 Lönnerdal B: Preclinical assessment of infant formula. Ann Nutr Metab 2012;60:196199.

72 Szajewska H: The role of systematic data reviews in safety assessment of infant nutrition. Ann Nutr Metab 2012;60:204-207.

$\rightarrow 73$ Welch RW, Antoine JM, Berta JL, et al: Guidelines for the design, conduct and reporting of human intervention studies to evaluate the health benefits of foods. Br J Nutr 2011;106(suppl 2):S3-S15.

74 Bier DM: Safety standards in infant nutrition: a United States perspective. Ann Nutr Metab 2012;60:192-195.

75 Hernell O: Current safety standards in infant nutrition - a European perspective. Ann Nutr Metab 2012;60:188-191. 


\section{Erratum}

In the article by Koletzko et al.: Quality and Safety Aspects of Infant Nutrition. Ann Nutr Metab 2012;60:179-184 (DOI:10.1159/000338803), the last sentence in the Acknowledgement has to read:

We thank Abbott Nutrition, Danone Research, Dairy Goat Cooperative, DSM Nutritional Products, Hipp GmbH, Mead Johnson Nutritionals and United Pharmaceuticals for additional support through unrestricted educational grants. 